\title{
Prem Phyak*
}

\section{Epistemicide, deficit language ideology, and (de)coloniality in language education policy}

https://doi.org/10.1515/ijsl-2020-0104

Received October 6, 2020; accepted October 15, 2020

Abstract: The purpose of this paper is to analyze how research approaches and methods in language education policy could serve to erase local multilingualism and its associated epistemologies while reproducing inequalities of languages. This paper builds on "epistemicide" (Santos, Boaventura de Sousa. 2014. Epistemologies of the South: Justice against epistemicide. New York: Routledge) to critique how the knowledge constructed on the basis of the evidence collected by using research questions in binary/conflictual terms misrepresents the real experiences and voices of multilingual participants, particularly those from languageminoritized communities. This paper argues that advancing research and building educational practices upon the lived experiences of the people, particularly Indigenous and ethnic minorities, could help us resist the destruction of languages, epistemologies, and linguistic/epistemic self-determination of communities. I use the case of Nepal not only because I am familiar with its historical, sociopolitical, and cultural contexts (so I can provide an insider's reflective perspective), but also because Nepal's case offers new insights into understanding language ideological issues in the discourses of language education policies from the vantage point of "peripheral multilingualism" (Pietikäinen, Sari \& Helen KellyHolmes. 2013. Multilingualism and the periphery. Oxford: Oxford University Press).

Keywords: decoloniality; deficit language ideology; epistemicide; language policy; multilingualism

\section{Introduction}

Applied linguists have long been critical about how prevalent monolingual policies and ideologies are erasing linguistic diversity, undermining epistemic

Correction note: A spelling error was corrected in the title after online publication March 11, 2021. The word "decifit" was changed to "deficit".

*Corresponding author: Prem Phyak, Department of English, The Chinese University of Hong Kong, Hong Kong, Hong Kong SAR, E-mail: p.phyak@cuhk.edu.hk 
diversity, and perpetuating language-based colonial/hegemonic global order within and across nation-states (e.g. Canagarajah 1999; Phillipson 1992; Tollefson 2013; Tupas 2015); yet, the scholarship that brings out the voices, struggles, and epistemologies from the periphery, particularly from language-minoritized and Indigenous communities, continue to be underrepresented in policymaking processes. Indeed, the critique of linguicide, epistemicide, and unequal language policies are deemed problematic for policymakers and the dominant public sphere. Working with teachers, teacher educators, Indigenous communities (including youth), journalists, and policymakers on issues concerning multilingualism and language education policy in Nepal, I have observed significant gaps between the growing scholarship that advocates for multilingual education policy and the dominant understanding about what counts as "a legitimate language" (Bourdieu 1991) in education. Regardless of the substantive research and advocacy by scholars around the globe, language policy discourses and even empirical research are still dominated by monolingual ideologies and epistemologies which misrecognize the lived experiences of the people in the periphery (May 2013). This paper takes up the case of Nepal, a multilingual and multiethnic nation-state, to unpack this issue.

The case of Nepal is not unique, but offers some common dynamics that are worth exploring. Nepal is a multilingual, multiethnic, and multicultural country, ${ }^{1}$ and its language policy has been a critical topic in national political debates. Officially, Nepal adopted a one-nation-one-language policy until the 1990s to build strong Nepali monolingual nationalism by delegitimizing its linguistic and cultural diversity (Weinberg 2013). Some scholars have advanced critical research and been critical about this policy, articulately arguing that such a policy reproduces linguistic hierarchies and perpetuates linguistic injustice, particularly for the Indigenous and ethnic minority communities whose "mother tongues" are different from the official language, Nepali (Awasthi 2008; Giri 2011). After a major political change in 2006, when a monarchical democracy ended in favor of fully representative and structurally decentralized federal democracy, Nepal officially defined its identity, in the new constitution, as a "multilingual, multicultural, and multiethnic" nation-state, and adopted policies to allow the use of mother tongues in schools, government offices, and other public spheres. The constitution mentions that citizens will not be discriminated based on their language, ethnicity,

1 In Nepal, 129 different named languages have been identified; 63 communities and 125 groups are recognized as Indigenous and ethnic groups, respectively.

2 The official Nepali as a named language is traditionally known as Khas, Parbate, or Gorkha Bhasha as the mother tongue of Khas Arya people. 
culture, religion, class, sex, and ideological background. More importantly, the constitution imagines a multilingual Nepali public sphere by creating and promoting a "multilingual policy" in government offices, schools and other spaces. However, this multilingual imagining is hardly observed in public spheres, particularly in education, where the discourses on language policies reproduce "inequalities of multilingualism" (Tupas 2015). Such discourses unquestionably accept the hegemony of English and Nepali at the expense of minoritized languages used by diverse communities across the country. Rather than making efforts, both at policy and program levels, to create multilingual school spaces, language policy actors, particularly government officials, headteachers, and school management committees, are now creating and promoting a new language policy, English as a medium of instruction (EMI), increasingly countering and erasing the legitimacy of multilingualism and creating a new form of linguistic injustice, epistemicide (Santos 2014).

Against the above backdrop, this paper analyzes how language education policy research could effectively serve to erase local multilingualism and its associated epistemologies, especially by framing its questions in binary/conflictual terms rather than using an inclusive multilingual approach in research and advocacy of policy and practice in the latter direction (see Piller 2016). It argues that advancing research and building educational practices upon the lived experiences of the people, particularly the Indigenous and ethnic minorities, could help us resist the destruction of languages, epistemologies, and linguistic/epistemic self-determination of communities. I use the case of Nepal not only because I am familiar with its historical, sociopolitical, and cultural contexts (so I can provide an insider's reflective perspective), but also because Nepal's case offers new insights into understanding language ideological issues in the discourses of language education policies from the vantage point of "peripheral multilingualism" (Pietikäinen and Kelly-Holmes 2013). On the one hand, Nepal's case, in general, is peripheral in the field of the sociology of language and, on the other, the epistemologies and ideologies of different peripheral communities such as Indigenous people, ethnic minorities, and rural villagers are often misinterpreted and invisibilized in language education policy discourses in Nepal. In this paper, I discuss the general implications of these issues by focusing my analysis on epistemicide and deficit ideology in language education policy discourses and practices. 


\section{My positionality and the research approach}

As a multilingual individual, I use three languages - $\mathrm{Limbu}^{3}$ (mother tongue), Nepali, and English. For me, all three languages are equally important. I use Limbu to connect myself with my family members and relatives in Nepal's rural hills and to participate in cultural events in cities. I speak Nepali with my colleagues and neighbors from other linguistic backgrounds. I use English mostly for academic and professional purposes and to interact with my foreign friends. My multilingual self represents the struggles and experiences of multilingual speakers, particularly the Indigenous peoples, whose mother tongues are hardly visible in dominant public spheres. My research work is informed by an engaged approach (Davis and Phyak 2017) which focuses on trust-building with the researched communities and on creating an environment where participants can openly discuss multiple and contested language issues (e.g. sociopolitical, educational, and cultural) in education. This approach pays attention to critiquing the underlying assumptions of dominant language policies and their impacts on the lives of language-minoritized people. One crucial aspect of this approach is researchers' longer-term engagement as a co-participant and co-member of the community where the study is carried out.

Working with communities and the general public is always a rewarding experience in terms of understanding critical issues concerning multilingualism. My engaged research approach to language education policy focuses not on collecting data by using a fixed set of questionnaire, but on engaging participants in dialoguing about the existing knowledge, ideology, and language situation. Dialoguing involves a series of informal interactions with the participants in community meetings, workshops, and seminars. It is critical, reflective, inclusive, and transformative. In the engaged approach, dialogues are based on a situated and historical understanding of participants' local context, lived experience, and language practices. For example, rather than asking either-or questions about language choice, I and my participants engage in unpacking the historical and sociopolitical conditions that shape language choice and co-construct situated and alternative perspectives of language policy. As a member of an Indigenous community, ${ }^{4}$ we share our stories of why and where we use our mother tongues, Nepali, and English for various purposes. Using mostly Limbu, we analyze why

3 Limbu is the language of the Limbu Indigenous people in Nepal. This language is spoken in some states of India as well.

4 I was born and brought up in a Limbu Indigenous family and community in rural village of Nepal. Limbu people in the village speak Limbu and Nepali in family and community. But English is hardly used in daily conversation. 
schools and communities are not using mother tongues although they have an important role in learning new languages and academic skills.

Informed by critical ethnographic approaches (Martin-Jones and Martin 2017; Thomas 1993), the engaged approach focuses on how multilingualism impacts participants' sense of belonging, acquisition of new knowledge, understanding of their surroundings, and eventually building a just society. It digs deep into the ideological issues in language policies and engages participants, mostly multilingual and minoritized people in the periphery, in reimagining an equitable language policy. The stories of minoritized peoples' struggles living in the periphery are complex and insightful, firmly resisting binary assumptions and artificial borders of languages and providing critical insights into creating equitable multilingual policies and practices (Pietikäinen and Kelly-Holmes 2013). The participants I work with are from the Indigenous communities (youth, parents, and teachers). Most of them are bilingual (with Nepali and mother tongue proficiency) and some of them are multilingual (with Nepali, English, and mother tongue proficiency). Most parents I work with are subsistence farmers and do not have literacy skills; they have never attended formal schooling. However, they have rich multilingual, multicultural, and multi-epistemological resources. They can tell folktales in their mother tongues and teach about many things such as weaving, making liquors, and preserving food. Their language practices are fluid and embrace multilingualism as part of their life. However, they have shown their concerns about unequal language policies and practices that have denied space for their mother tongues in education. For example, one parent says that "all languages are equally important. The use of mother tongue is necessary for the community building. Nepali and English are used for communication formal settings. But schools focus only on English these days.” During our dialogues, the participants argue that schools should play "an important role to promote all languages" and Indigenous youth need "to maintain mother tongues for cultural and social development".

Although multilingualism is integral to Indigenous communities, the agenda of multilingual education has been a contested issue in Nepal. Its relevance has been questioned in the dominant public sphere by indexing it as a mere "ethnic agenda". It is described as "harmful for Nepali nationalism and development". In a series of seminars with researchers, political leaders, aid workers, teachers, and parents, multiple issues such as parents' negative attitudes towards mother tongue and increasing demand for English are put at the forefront to counter the relevance of multilingual education. While these issues sound legitimate on the surface, they carry deep ideological baggage. In unpacking these ideologies, I explore the following three questions/comments to theorize how language education policy research and discourses, which lack a critical and in-depth understanding of 
historicity and political situatedness, support epistemicide and deficit language ideology.

- Parents and minoritized communities do not like multilingual education. So why are you talking about multilingual education? We just need English medium education in this modern age. Multilingual education creates more problems. ${ }^{5}$

- Multilingual language policy is not a local agenda in Nepal. It is imported and imposed by outsiders. Such policies are not good for our social harmony.

Although these comments are situated in Nepal's context, they are global in nature and deeply rooted in the history of monolingual ideologies in second-language acquisition and applied linguistics (May 2013). To respond to these comments, we need to analyze their historical roots and examine the epistemologies they promote. Doing so further requires us to examine the theories of epistemicide and deficit language ideology to unpack how such comments reproduce colonial ideologies and misrecognize local epistemologies in language education. My examples are drawn from my ongoing ethnographic study of language policies and multilingualism in Nepal. Next, I analyze how the above comments reproduce colonial ideologies which eventually contribute to epistemicide.

\section{Epistemicide and the politics of questioning through research}

The comments in the bulleted points above have come from researchers (in language policy and quality education), head teachers, and local government representatives. In three discussions organized by the Education Journalists' Group (EJG) in Nepal, I was invited as a resource person to share my research findings on language education. My presentations had focused on global practices and the local realities in language education policies and approaches to support language-minoritized and Indigenous children for quality learning. Taking a multilingual perspective, I presented why it is important to build on children's home languages, skills, and knowledge to create a safe and inclusive learning environment. I told the narratives of how students coming from languageminoritized groups and Indigenous communities are struggling to access knowledge from the national curricula and how they are not investing cognitively

5 These comments have been collected from multiple seminars and talks organized by local communities, journalists, Indigenous organizations, and universities between 2017 and 2020 in Nepal. The comments are translated from Nepali. 
in learning processes in a context where schools are unable to create a multilingual space (e.g. Cummins 2007). I discussed various models, such as duallanguage approach (Torres-Guzmán 2007), community-based schooling (McCarty and Watahomigie 1998), translanguaging (García and Kleyn 2016), language awareness (Jessner 2018), and identity texts (Cummins and Early 2010) that could help teachers support language-minoritized multilingual students. After my brief presentations, as usual, there was a long question-answer session. Each participant had an opportunity to comment and share their thoughts on language education policies. While most participants, particularly teachers and parents, appreciated what I had shared with them, in one of the discussion series, three participants, who self-identified as researchers and teacher educators (henceforth commentators), made two thought-provoking comments, as mentioned above. They explained their contention regarding multilingual education policy. While questioning the relevance of multilingualism in education, they consistently referred to what parents have said to them in their study. For them, multilingual education is not necessary because "parents do not accept it."

The commentators mentioned that they had conducted a study to explore parents' "choice" of language and found that most Indigenous parents "preferred English" and "rejected mother tongue education". One of the commentators was arguing that "the majority of parents and children do not like to use their mother tongues in education" because "they don't see the value in their mother tongues". While explaining the process of the study, he mentioned that he had used a fixed set of questionnaires to survey parental language "choice" and "preference" in education. Although empirical evidence increasingly justifies the relevance of using children's home languages for strong cognitive, socio-cultural, and academic knowledge and skills (Cenoz and Genesee 1998; Cummins 2007), arguments that dismiss the value of home languages are still prevalent and remain hegemonic in public discourses. Yet, the historicity, sources, and consequences of such dominant assumptions and arguments are underexplored, particularly in peripheral contexts, such as Nepal, where discourses on language education policies and education reforms are underresearched and inadequately theorized.

First, the knowledge based on the evidence collected from a set of questionnaires, as mentioned by the commentator, erases the lived experiences of language-minoritized and Indigenous people who have endured oppressive, both official and non-official, language policies. As mentioned above, the Indigenous communities give value to all languages they speak, but they are worried about the exclusion of their home language in education. In Nepal, two dominant ideologies, monolingual nationalism and neoliberal development discourse (Sah 2020; 
Sharma and Phyak 2017), have not only contributed to diminishing the relevance of local linguistic diversity but also supported the erasure of epistemologies that represent the lived experiences of language-minoritized and Indigenous people. Santos (2014) calls this phenomenon epistemicide, "a massive waste of social experience and, particularly, in the massive destruction of ways of knowing that did not fit the dominant epistemological canon" (238). The logic of "choice" of languages in a multilingual context misrecognizes the complexities of multilingual experiences and supports the "we-vs-them” discourse (Phyak 2013). The notion of "choice" itself is not a neutral concept; rather it carries neoliberal values that reproduce the power of free market economy (Price 2014). As a politically charged concept, "choice” is deployed as a discursive tool to reproduce sociopolitical, economic, and cultural capitals, wrought by the neoliberal market, of a particular language (here English) and to validate the legitimacy of monolingual ideologies in education. For example, one of the commentators in the workshop, questioning the relevance of multilingual education, asked his research participants, mostly Indigenous peoples, an extremely misleading question: "which languages do you want your children to use and learn in school?” They were asked to choose between English and mother tongue. While asking this question, the commentator was communicating a specific set of values that keep the pressure on parents to choose English or mother tongue. Indeed, such questions do not represent multilingual epistemologies; rather they firmly support "monolingual mindset” (Clyne 2008). More importantly, they misrecognize what multilingual parents in the periphery actually need for their children's education.

After having this discussion, I had a series of "engaged dialogues" (Davis and Phyak 2017) with Indigenous parents and teachers with whom I have been working. As mentioned above, our dialogues were ethnographic and included reflective conversations on language practices in school, family, community, and media as the participants have observed and experienced. Most of our dialogues focus on understanding the ideological meanings of language policy discourses and practices. Due to space limitation, I am not able to discuss all the issues, but I would like to focus on the way I framed the questions to begin the dialogues with the participants.

a. Do you want your children to be proficient in English only?

b. Do you want your children to be proficient in Nepali only?

c. Do you want your children to be taught in mother tongue only?

d. Do you want your children to be proficient in all of these languages?

e. Do you want your children to be proficient in other subjects such as social studies, mathematics, and science? 
In my engaged approach, rather than asking rigid binary questions, I ask participants to share their thoughts on the importance of languages they use and are exposed to. I ask these questions not to elicit specific answers but to generate further dialogues on the values of languages. As mentioned above, such questions are grounded in an ethnographic understanding of local language policy discourses and participants' lived experiences - what they have seen, observed, and experienced. When asked to choose only one language (questions a, b, and c), the participants chose "English" only. Most researchers, as discussed earlier, ask this question and claim that parents need English-only education and do not like mother tongue education. However, such questions promote monolingual ideologies and strengthen the historical legacy of monolingualism in education policies. During discussions, the Indigenous parents had a common view that they would like their children to be proficient in all three languages (English, Nepali, and mother tongue) and all the content subjects such as social studies, mathematics, and science. By doing this, they defy the either-or question and uphold an inclusive multilingual epistemology of language education policy. These responses indicate that "framing" (Goffman 1974) of research questions is critical to erasing or embracing multilingual epistemologies. As Piller (2016) aptly puts it, such questions promote the "monolingual ways of seeing multilingualism" that reproduce the power of English as the only legitimate language in education, particularly in the periphery context where it is rarely used in real-life situations. Framing and asking binary choice questions, as discussed here, misrepresent real perspectives about language and erase the lived multilingual experiences of Indigenous peoples. This kind of "erasure” (Gal and Irvine 1995) not only promotes linguistic hierarchy and inequalities of multilingualism (Tupas 2015), but also destroys language-minoritized people's epistemologies. Language policy decisions based on the evidence collected from such either-or questions continue to reinforce the history of exclusionary language policies and disregard language-minoritized people's struggles and agency in making sense of the hierarchical linguistic situation of Nepal.

\section{Deficit language ideology and colonial mentality}

The sociopolitical and economic power of English wrought by colonial and neoliberal ideologies are often overlooked in either-or questions for language choice. The commentators who were questioning the relevance of multilingual education did not ask any further questions about why the parents wanted to opt 
for English but not Nepali and/or their mother tongue. Although Nepal has never been colonized militarily/politically, it has had a long history of colonial mentality in language education policies (Awasthi 2008). Colonial mentality refers to the psychology of inferiority constructed by oppressive language policies and unequal sociopolitical structures (David and Okazaki 2006). This mentality upholds a deficit ideology that justifies inequalities as the outcome of deficiencies (intellectual, economic, and political) of the marginalized groups (Gorski 2011). A deficit ideology disregards the fact that social inequalities, including language inequalities, are shaped by unequal sociopolitical structures and policies, and it blames the individuals and communities whose languages/language practices have already been marginalized. The framing of either-or questions carries a deficit language ideology that forces multilingual participants to choose between English or mother tongues, but not both of them. Such deficit views collected by using binary questions reproduce, but do not challenge, Western colonial language ideologies.

For Dorian (1998), Western language ideologies promote an "ideology of contempt" towards minoritized languages and uphold the view that "bilingualism [multilingualism] is onerous". The commentators' views, as given above, are an epitome of how negative attitudes towards minoritized languages are created and reproduced through research in language policy. While questioning the relevance of multilingual education and highlighting the importance of English, the commentators' views generate contemptuous assumptions about minoritized languages. In Nepal, the ideology of contempt has already been a powerful tool to counter transformative policies such as mother-tongue-based multilingual education (MTB-MLE). According to this policy, children's mother tongues should be used as a medium of instruction up to Grade 3 and taught as subjects across the grades (Fillmore 2020). Previous studies have shown that the MTB-MLE policy is now being replaced by English medium policy from the early grades (Phyak and Sharma 2020; Sah and Karki 2020). English is not only taught as "a compulsory subject” from the first grade, but is used as a sole medium of instruction to teach all academic content subjects. This policy is based on what the commentators have argued: "we just need English medium education in this modern age". While such arguments index English as a symbol of modernity (Blommaert 2007), it diminishes the relevance of multilingualism as onerous in education. My ethnographic investigation of classroom pedagogies shows that both students and teachers are not able to fully invest their cognitive and linguistic knowledge in teaching-learning activities in monolingual English medium classes. In the early grades, students just keep silent and follow what their teachers, who themselves cannot provide explicit instructions in English, ask them to do (Phyak and Sharma 2020). In a series of dialogues, teachers are provided with opportunities to critically reflect on their classroom pedagogies and analyze how such a monolingual policy is affecting students' access to 
knowledge and participation in classroom activities. While teachers agree with the need for English language teaching (which is already in place), they are critical about the monolingual EMI policy which, as one of the teacher recounts, "has turned all classes into English language classes and posed serious challenges for quality learning”. For the teachers, EMI policy is ideological; it focuses on the dominant assumption of English as a global language and creates a hierarchy of languages. Such unequal indexicality of languages, supported by the evidence collected from faulty research questions (as mentioned above), not only fails to recognize the historical struggles and epistemologies of language-minoritized people, but also promotes Eurocentric epistemologies.

The Eurocentric epistemologies focus on the understanding of the nation-state as an imagined community of people speaking one standard language (Anderson 2006). The commentators' perspective that multilingual education policies are "not good for our social harmony" represents their Eurocentric knowledge about nationstate and language. Such homogenous epistemologies consider multilingualism and cultural diversity as a problem for education and society. As Santos (2014) argues, this sort of epistemology "involves the destruction of the social practices and the disqualification of the social agents that operate according to such knowledges" (153). The commentators' views, as mentioned above, indeed misrecognize multilingual speakers' socio-cultural, political, and historical experiences living with multiple languages in the periphery contexts (e.g. minority and Indigenous communities). Seeing multilingualism as a problem means to consider multilingual individuals and communities and their epistemologies as a problem.

\section{Conclusions}

In this paper, I have tried to unpack how multilingual epistemologies are erased in language policy research and discourses, taking the case of Nepal. Although my arguments are based on one specific context, the lessons drawn from this paper can be insightful to analyze how multilingual speakers' epistemologies, ideologies, and identities are misrepresented in empirical language policy research. First, research questions related to language choice could only reproduce colonial and neoliberal epistemologies about what counts as a legitimate language in education. As such questions do not approach "linguistic epistemes from ethnographic or insider perspectives" (James 2020: 32), they are unable to represent the lived experiences, ideologies, and epistemologies of multilingual individuals and communities who have endured oppressive language policies. Asking either-or questions is just about doing a "politics of methodology" (Ndimande 2012) to counter multilingual epistemologies constructed around the 
struggles and experiences of language-minoritized and Indigenous communities. Such questions promote binary distinctions between English and mother tongues and divide the privileged and the marginalized, and the monolinguals and the multilinguals. The either-or question is an example of what Piller (2016: 32) calls "English-monolingual ways of seeing multilingualism" that "limit our vision and constrain our understanding” about historical and locally situated contexts of multilingualism. So it is not multilingualism, but the colonial ways of seeing multilingual-as-a-problem that creates the problem for social harmony; it destroys rich linguistic, cultural, and epistemological diversities. Indeed, as discussed in this paper, the research questions that promote monolingual ideologies do not represent parents' real perspectives and experiences in multilingual contexts. So, contrary to what the commentators have claimed above, binary research questions, not the discourses of multilingual education, could be considered an "outsiders' agenda”, which carries the historical legacy of Western colonial language ideologies.

Secondly, the issues discussed in this paper imply that language policy research should focus on an engaged approach (Davis and Phyak 2017; Langman 2014) that builds on ethnographic dialogues and critical analyses of ideologies in language policy discourses. Such approaches embrace the lived experiences of multilingual communities and espouse "epistemologies of the South" (Santos 2014). Such epistemologies include "a set of inquiries into the construction and validation of knowledge born in struggle, of ways of knowing developed by social groups as part of their resistance against the systematic injustice and oppression caused by capitalism, colonialism, and patriarchy" (Santos 2014: x). As discussed in this paper, it is important to engage language-minoritized communities in dialoguing about the impacts of dominant language policies in their communities. The either-or questions which promote Eurocentric epistemologies are unable to represent their perspectives and epistemologies, and as Santos (2014) claims, provide weak answers to the questions that "do not challenge the horizons of possibilities”. Challenging the colonial mentality and deficit language ideology requires us to participate in a liberating project of decoloniality (Smith 1999). Maldonado-Torres (2016) defines decoloniality as

efforts at rehumanizing the world, to breaking hierarchies of difference that dehumanize subjects and communities and that destroy nature, and to the production of counterdiscourses, counter-knowledges, counter-creative acts, and counter-practices that seek to dismantle coloniality and to open up multiple other forms of being in the world. (10)

Participating in a decolonial project engages us in posing counter questions that recognize the struggles and knowledge of the historically marginalized communities. Collaborative dialogues grounded in ethnographic insights could be one of 
the ways to engage language policy actors, particularly language-minoritized people, in the project of decoloniality. However, as Smith (1999) argues, decolonization should not be understood as "a total rejection of all theory or research or Western knowledge”, rather it is "about centering our [Indigenous] concerns and worldviews and then coming to know and understand theory and research from our [Indigenous] own perspectives and for our [Indigenous] own purposes" (39). For this, research and other forms of knowledge-building processes in language education policy should integrate both knowledge and actions to fully embrace multilingual people's lived experiences in historical and contemporary linguistic complexities. Such projects should be informed by our commitment towards “epistemic justice” (Fricker 2007), which recognizes languageminoritized speakers as an epistemic being.

Acknowledgments: I am grateful to Shyam Sharma, Bal Krishna Sharma, and an anonymous reviewer for their comments on the initial version of this paper.

\section{References}

Anderson, Bendict. 2006. Imagined communities: Reflections on the origin and spread of nationalism. London \& New York: Verso Books.

Awasthi, Lava Deo. 2008. Importation of ideologies from Macaulay Minutes to Wood Commission. Journal of Education and Research 1(1). 21-30.

Blommaert, Jan. 2007. Sociolinguistics and discourse analysis: Orders of indexicality and polycentricity. Journal of Multicultural Discourses 2(2). 115-130.

Bourdieu, Pierre. 1991. Language and symbolic power. Cambridge: Polity.

Canagarajah, Suresh A. 1999. Resisting linguistic imperialism in English teaching. Oxford: Oxford University Press.

Cenoz, Jasone \& Fred Genesee. 1998. Beyond bilingualism: Multilingualism and multilingual education. Clevedon: Multilingual Matters.

Clyne, Michael. 2008. The monolingual mindset as an impediment to the development of plurilingual potential in Australia. Sociolinguistic Studies 2(3). 347-366.

Cummins, Jim. 2007. Rethinking monolingual instructional strategies in multilingual classrooms. Canadian Journal of Applied Linguistics 10(2). 221-240.

Cummins, Jim \& Margaret Early. 2010. Identity texts: The collaborative creation of power in multilingual schools. Oakhill: Trentham Books.

David, E. J. R. \& Sumie Okazaki. 2006. Colonial mentality: A review and recommendation for Filipino American psychology. Cultural Diversity and Ethnic Minority Psychology 12(1). 1-16.

Davis, Kathryn A. \& Prem Phyak. 2017. Engaged language policy and practices. London \& New York: Routledge.

Dorian, Nancy C. 1998. Western language ideologies and small-language prospects. In Lenore A. Grenoble \& Lindsay J. Whaley (eds.), Endangered languages: Language loss and community response, 3-21. Cambridge: Cambridge University Press. 
Fillmore, Naomi. 2020. Mother tongue-based multilingual education in Nepal: Past, present, and emerging trends. In Alexander W. Wiseman (ed.), Annual review of comparative and international education 2019, 231-254. Melbourne: Emerald Publishing Limited.

Fricker, Miranda. 2007. Epistemic injustice: Power and the ethics of knowing. Oxford: Oxford University Press.

Gal, Susan \& Judith T. Irvine. 1995. The boundaries of languages and disciplines: How ideologies construct difference. Social Research 62(4). 967-1001.

García, Ofelia \& Tatyana Kleyn. 2016. Translanguaging with multilingual students: Learning from classroom moments. London \& New York: Routledge.

Giri, Ram Ashish. 2011. Languages and language politics: How invisible language politics produces visible results in Nepal. Language Problems and Language Planning 35(3). 197-221.

Goffman, Erving. 1974. Frame analysis: An essay on the organization of experience. Cambridge, Mass: Harvard University Press.

Gorski, Paul C. 2011. Unlearning deficit ideology and the scornful gaze: Thoughts on authenticating the class discourse in education. Counterpoints 402. 152-173.

James, Costa. 2020. Through the looking glass: Politics of language and nature, and the disqualification of vernacular forms of knowledge. Language, Culture and Society 2(1). 126-134.

Jessner, Ulrike. 2018. Language awareness in multilingual learning and teaching. In Peter Garrett \& Joseph M. Cots (eds.), The Routledge handbook of language awareness, 257-274. London \& New York: Routledge.

Langman, Juliet. 2014. Translanguaging, identity, and learning: Science teachers as engaged language planners. Language Policy 13(2). 183-200.

Maldonado-Torres, Nelson. 2016. Outline of ten theses on coloniality and decoloniality. Paris: Frantz Fanon Foundation.

Martin-Jones, Marilyn \& Deirdre Martin (eds.). 2017. Researching multilingualism: Critical and ethnographic perspectives. London \& New York: Routledge.

May, Stephen (ed.). 2013. The multilingual turn: Implications for SLA, TESOL, and bilingual education. London \& New York: Routledge.

McCarty, Teresa L. \& Lucille J. Watahomigie. 1998. Indigenous community-based language education in the USA. Language, Culture and Curriculum 11(3). 309-324.

Ndimande, Bekisizwe S. 2012. Decolonizing research in postapartheid South Africa: The politics of methodology. Qualitative Inquiry 18(3). 215-226.

Phillipson, Robert. 1992. Linguistic imperialism. Oxford: Oxford University Press.

Phyak, Prem. 2013. Language ideologies and local languages as the medium-of-instruction policy: A critical ethnography of a multilingual school in Nepal. Current Issues in Language Planning 14(1). 127-143.

Phyak, Prem \& Bal Krishna Sharma. 2020. Functionality of English in language education policies and practices in Nepal. In Ram Ashish Giri, Anamika Sharma \& James D’Angelo (eds.), Functional variations in English, 321-335. Cham: Springer.

Pietikäinen, Sari \& Helen Kelly-Holmes. 2013. Multilingualism and the periphery. Oxford: Oxford University Press.

Piller, Ingrid. 2016. Monolingual ways of seeing multilingualism. Journal of Multicultural Discourses 11(1). 25-33. 
Price, Gareth. 2014. English for all? Neoliberalism, globalization, and language policy in Taiwan. Language in Society 43(5). 567-589.

Sah, Pramod Kumar. 2020. Reproduction of nationalist and neoliberal ideologies in Nepal's language and literacy policies. Asia Pacific Journal of Education. https://doi.org/10.1080/ 02188791.2020 .1751063$.

Sah, Pramod K. \& Jeevan Karki. 2020. Elite appropriation of English as a medium of instruction policy and epistemic inequalities in Himalayan schools. Journal of Multilingual and Multicultural Development. 1-15. https://www.tandfonline.com/doi/full/10.1080/ 01434632.2020.1789154 (accessed 20 August 2020).

Santos, Boaventura de Sousa. 2014. Epistemologies of the South: Justice against epistemicide. New York: Routledge.

Sharma, Krishan Bal \& Phyak Prem. 2017. Neoliberalism, linguistic commodification, and ethnolinguistic identity in multilingual Nepal. Language in Society 46(2). 231-256.

Smith, Linda Tuhiwai. 1999. Decolonizing methodologies: Research and Indigenous peoples. Dunedin: University of Otago Press.

Thomas, Jim. 1993. Doing critical ethnography. New York: Sage.

Tollefson, Jame W. (ed.). 2013. Language policies in education: Critical issues, 2nd edn. New York \& Abingdon: Routledge.

Torres-Guzmán, Maria E. 2007. Dual language programs: Key features and results. In Ofelia Garcia \& Colin Baker (eds.), Bilingual education and bilingualism, 50-63. Clevedon: Multilingual Matters.

Tupas, Ruanni. 2015. Inequalities of multilingualism: Challenges to mother tongue-based multilingual education. Language and Education 29(2). 112-124.

Weinberg, Miranda. 2013. Revisiting history in language policy: The case of medium of instruction in Nepal. Working Papers in Educational Linguistics 28(1). 61-80.

Supplementary Material: The online version of this article offers supplementary material (https:// doi.org/10.1515/ijsl-2020-0104). 